\title{
Does legislative change affect the use and duration of compulsory treatment orders?
}

\author{
Associate Professor Ruth Vine \\ Executive Director NorthWestern Mental Health \\ Royal Melbourne Hospital \\ Grattan St Parkville \\ 3050 \\ Ruth.vine@mh.org.au
}

Ms Holly Tibble

Research Assistant

School of Population and Global Health

University of Melbourne

235 Bouverie St

Parkville 3053

Holly.tibble@unimelb.edu.au

Professor Jane Pirkis

School of Population and Global Health

University of Melbourne

235 Bouverie St

Parkville 3053

j.pirkis@unimelb.edu.au

\section{Professor Matthew Spittal}

School of Population and Global Health

University of Melbourne

235 Bouverie St

Parkville 3053

m.spittal@unimelb.edu.au

\section{Professor Fiona Judd}

Menzies Institute for Medical Research, University of Tasmania,

17 Liverpool St

Hobart 7000

Fiona.judd@ths.tas.gov.au 


\title{
Does legislative change affect the use and duration of Compulsory Treatment Orders?
}

\author{
Ruth Vine $e^{1,2}$ \\ Holly Tibble $^{3}$ \\ Jane Pirkis ${ }^{3}$ \\ Fiona Judd ${ }^{2,4}$ \\ Matthew J Spittal ${ }^{3}$ \\ Word count 4958
}

Abstract

Objective: Victoria, Australia introduced reformed mental health legislation in 2014. The Act was based on a policy platform of recovery oriented services, supported decision making and minimisation of the use and duration of compulsory orders. This paper compares service utilisation and legal status after being on a community treatment order under the Mental Health Act 1986 (Vic) with that under the Mental Health Act 2014 (Vic).

Methods: We obtained two distinct data sets of persons who had been on a community treatment order for at least three months and their subsequent treatment episodes over two years under the MHA and/or as an inpatient for the periods 2008 - 2010 (MHA 1986) and $2014-2016$ (MHA 2014). The two sets were compared to assess the difference in use, duration and odds of having a further admission over two years. We also considered the mode of discharge - whether by the treating psychiatrist, external body or through expiry.

Results: Compared with the MHA 1986, under the MHA 2014 index community treatment orders were shorter (mean 227days compared with 335 days); there was a reduction in the mean number of community treatment orders in the two years following the index discharge - 1.1 compared with 1.5 (IRR $=0.71,95 \% \mathrm{Cl}=0.63-0.80)$; and a $51 \%$ reduction in days on an order over two years. There was a reduction in the number of subsequent orders for those whose order expired or was revoked by the psychiatrist under the MHA 2014 compared to those under the MHA 1986. The number of orders which were varied to an inpatient order by the authorised psychiatrist was notably greater under the MHA 2014.

Conclusion: The reformed MHA has been successful in its intent to reduce the use and duration of compulsory orders in the community. The apparent increase in return to inpatient orders raises questions regarding the intensity and effectiveness of community treatment and context of service delivery.

\section{Keywords}

Community Treatment Order, Mental Health Act, service utilisation

\footnotetext{
${ }^{1}$ NorthWestern Mental Health, Parkville, VIC, Australia

2 Department of Psychiatry, The University of Melbourne, Melbourne, VIC, Australia

${ }^{3}$ Melbourne School of Population and Global Health, The University of Melbourne, Melbourne, VIC, Australia

${ }^{4}$ Menzies Institute for Medical Research, University of Tasmania, Hobart, TAS, Australia
} 
$\underline{\text { Introduction }}$

Mental health legislation sets out the requirements which must be met to permit compulsory treatment of those with severe mental illness, including those interventions which must be reported and the requirement for external review or oversight. Current mental health legislation includes provision for compulsory treatment to be provided in community settings (Community Treatment Order; CTO). These are widely used, especially in Victoria (Light et al., 2012). However, the perceived utility of СTO by clinicians is at odds with the findings of much of the research in the area (Little, 2018; Hastings and Gray, 2016; Rugkåsa et al., 2014).

Studies have suggested that CTOs of longer duration are associated with reduced risk of relapse (Swartz et al., 2010) and that CTOs do support medication adherence. These benefits are particularly apparent while the CTO is in effect (Harris et al., 2018). Debate on the effectiveness of CTOs is ongoing (Rugkåsa et al., 2014; Burns and Molodynski, 2014). Maughan et al proposed that future research should aim to distinguish between CTO recall and revocation and different patterns of community contact, as this would assist in differentiation between СTO process and outcome (Maughan et al., 2014).

Controversy about the use of CTOs relates not only to concerns about their effectiveness, but also to concerns about an individual's rights of autonomy and freedom of choice, and access to treatment (Burns, 1999; Swartz et al., 2010).Recent developments in mental health legislation have placed greater emphasis on compatibility with human rights consistent with the provisions of the Convention on the Rights of Persons with Disability (United Nations, 2006; Kallert Thomas W, 2011).

Victoria, Australia implemented forward thinking mental health legislation in 1986 (Mental Health Act 1986 (Vic)). The MHA 1986 introduced external review by the Mental Health Review Board (MHRB) and provision for involuntary treatment in the community - СТO. Although the MHA 1986 was amended on many occasions it was deemed not compatible with the Victorian Charter of Human Rights and Responsibilities, and reformed legislation was enacted in July 2014 (Victorian Government, 2014; Victorian Government, 2006). This was outlined by the then Minister for Mental Health, the Honourable Mary Wooldridge to the parliament in February 2014 (Wooldridge, 2014b). The Mental Health Act 2014 (Vic) was based on a policy platform of recovery oriented care. It was explicit in its intention to minimise the use and duration of compulsory orders, treatment in the least restrictive way, and to promote supported decision making through mechanisms including the 
introduction of independent advocacy, nominated persons, independent second opinion and advance statements (Department of Health, 2012; Legislative Assembly, 2014; Wooldridge, 2014a).

The MHA 2014 commenced in July 2014 and introduced a staged process for compulsory status with restrictions on what treatment could be instituted in the first 24 hours (Table 1). It increased the threshold for compulsory care by requiring an immediate need for treatment to prevent 'serious' deterioration or 'serious' harm, and that the order must be 'immediately' revoked if the criteria no longer apply. The MHRB was replaced by the Mental Health Tribunal (MHT) which had the power to make both Community and Inpatient Treatment Orders (ITO). The discretion of the Authorised Psychiatrist (AP) to determine treatment and detention as a Compulsory Patient was reduced to 28 days. Any order for a longer time could only be made by the MHT. The duration an order could be made (by the MHT) was reduced to a maximum of six months (compared to 12 months by the AP under the MHA 1986) for a current inpatient and 12 months for a community patient with requirement to justify the length of the order made. The MHA 2014 also increased external oversight with the creation of a Mental Health Complaints Commissioner. The Act emphasised supported decision making over substituted decision making. The principles included that persons should be allowed to make decisions about their treatment that involve a "degree of risk" (MHA (2014), s11 (d). Commencement of the MHA 2014 was accompanied by a comprehensive information and education package supported by funding for additional MHA support staff in every area mental health service.

There were also substantial changes to the service system from 1986 to 2014, with progressive closure of large stand-alone services, increased funding to non-clinical community support services, and a preference for community based care over inpatient care. In a previous publication examining service utilisation and legal status following CTO termination under the MHA 1986, we reported that there was a significantly greater likelihood of subsequently requiring treatment as an involuntary patient if discharge from a CTO had been unplanned such as through expiry of the Order or by determination of the MHRB, rather than as part of discharge planning by the treating service (Vine $\mathrm{R}$ et al., 2016).

In this paper we explore whether there are any differences in the duration and frequency of use of СTOs under two mental health acts which differ in their emphasis on the rights of the individual, external determination and justification of the imposition of compulsory treatment. We hypothesised that the duration of the CTO would be shorter under the MHA 2014 compared with 
the MHA 1986, both because of a shift in the threshold for compulsory treatment, and a more assertive MHT. Related to this, we questioned whether there would be more episodes of compulsory care under the MHA 2014 because people may be more at risk of relapse if taken off an order earlier on in the course of the illness or relapse.

\section{Methods}

\section{Study design}

Two distinct data sets were obtained from the Department of Health and Human Services (DHHS). The first identified all individuals who had been on a CTO (under MHA 1986) for at least three months in 2008 and subsequent service utilisation over the 24 months post discharge or expiry of the CTO. This data set comprised 1478 individuals. The second data set identified all those who had been on a CTO of at least 3 months duration at December 2014 (under MHA 2014) and their subsequent service utilisation over two years. We considered the mode of termination of the CTO (whether by the AP, MHT or expiry) and whether the person was subsequently admitted or placed under an Order. The two data sets are from the same source such that we were able to compare the 2008 - 2010 outcomes with those under reformed legislation in $2014-2016$.

Ethical approval was obtained from the Melbourne Health Human Research Ethics Committee (No. 2013.109).

\section{Data Sources}

The DHHS Victoria administers the Client Management Interface/Operational Data Store (CMI/ODS) data system that records all registrations and contacts with state funded mental health services. Compulsory treatment can only be provided in the state funded and operated health services. The CMI/ODS records basic demographic information about patients as well as detailed information about the use of mental health services. The Department provided baseline data on individuals who met the inclusion criteria and follow-up data on any inpatient admissions and changes in mental health legal status. The data set included diagnosis.

\section{Statistical Analysis}

We report descriptive statistics of the samples, and associations between mode of discharge and key variables. We also undertook a direct comparison between the two data sets to assess the difference in the odds of having at least one admission within the 2 years following expiry or discharge. We carried out a comparison of the number of admissions and duration under a 
compulsory order under the two Acts. These were adjusted for discharge reason, sex, age, service location and duration of order. Logistic regression was used to determine predictors of subsequent orders within 2 years of index discharge. All analyses were undertaken in Stata version 15.1.

$\underline{\text { Results }}$

The data sets included 1478 patients who had been on a CTO for $>3$ months under the MHA 1986 (2008 -2010) and 1297 patients on a CTO for >3 months under the MHA 2014. Index community treatment orders were shorter under the MHA 2014. Median duration under the MHA 1986 was 335 days compared with 227 under the MHA 2014. Thirty-four per cent were less than 6 months under the MHA (2014) compared to only 20\% being less than 6 months under the MHA 1986 ( $p<$ 0.001)(Table 2).

\section{Mode of termination}

Under the MHA $198688 \%$ of patients were discharged from the CTO by the AP. A similar proportion (86\%) had the CTO ended by the AP under the MHA 2014, but a noticeable difference was that 410 of the 1297 patients had their CTO varied to an Inpatient order by the treating psychiatrist, rather than being discharged to voluntary status. We included these in the analysis on the basis that to exclude them would misrepresent the outcome of those on the СТО. These patients were included in the category revoked by the Authorised Psychiatrist. In a sensitivity analyses, it was found that the 410 patients on a 'vary order' had been on longer CTOs (31\% over a year vs. $24 \%$ ), were more likely to be male $(71 \%$ vs. $62 \%)$ and have a substance use disorder ( $13 \%$ vs. $7 \%$ ) but less likely to have a mood disorder (3\% vs. $9 \%$ ), compared to the remainder (887). Compared to the participants in the study period under the MHA $1986(n=1,478)$, those under the MHA $2014(n=1,297)$ had a higher proportion of index orders ending by expiry (9\% vs $6 \%$ ) (Table 2 ).

\section{Frequency of Episodes}

On average, participants had 1.5 further community treatment orders in the two years after index discharge under the MHA 1986, compared to 1.1 under the MHA 2014- a 29\% reduction (Table 3). If the discharge mode is disaggregated, the main difference is the reduction in number of episodes for those whose index CTO discharge was authorised by a psychiatrist ( $31 \%$ reduction) compared to only $14 \%$ for those revoked by a mental health tribunal (non-significant reduction). For inpatient treatment orders, there was a 22\% reduction between the MHA 1986 and MHA 2014. Index CTOs discharged by a MHT revocation had the least difference (17\%; non-significant reduction) while 
expired and psychiatrist discharged orders both had a significant reduction. For inpatient admissions, there was no meaningful change in incidence between the MHA 1986 and MHA 2014. Those on a varied order had significantly more CTOs (IRR $=1.43,95 \% \mathrm{Cl}=1.20-1.70)$ and inpatient admissions (IRR $=1.23,95 \% \mathrm{Cl}=1.09-1.37)$ than those who were discharged to voluntary status, while there were fewer ITOs (IRR $=2.75,95 \% \mathrm{Cl}=0.60-0.79)$.

\section{Duration of Subsequent Orders}

There was a $25 \%$ reduction in the number of days on orders (inpatient or community) over the following 2 years under the MHA 2014 compared with the MHA 1986 (Table 4). This represents a change from an average of 479 days (over two years) on an order, to 357 days under the MHA 2014. While this reduction is not significant for index CTOs discharged by MHT, those that expired lead to a 55\% reduction in days on order for the MHA 2014 compared to the MHA 1986 (95\% Cl: $35-68 \%$ ), and a $21 \%$ reduction for those discharges authorised by psychiatrist (95\% $\mathrm{Cl}: 11-30 \%)$. Time on order was higher for those whose orders were varied -454 vs 267 days (IRR $=1.70,95 \% \mathrm{Cl}=1.46-$ 1.98).

\section{Order Recurrence - Adjusted Analysis}

Further analysis was carried out to assess the difference in the odds of having at least one inpatient admission, community treatment order, or inpatient treatment order in the 2 years following discharge. Both analyses were adjusted for discharge reason, sex and age of the consumer, mental health service location and the number of days on order prior to discharge (Table 5). The admission odds ratios show that individuals were more likely to have an inpatient admission in the 2 years from discharge under the $2014 \mathrm{MHA}$, but there was no significant interaction between the two data periods for the treatment orders.

Those on a varied order had significantly higher odds of at least one subsequent admission (IRR = $16.22,95 \% \mathrm{Cl}=11.28-23.31)$, CTO $(\mathrm{IRR}=7.13,95 \% \mathrm{Cl}=5.40-9.43)$ and $\mathrm{ITO}(\mathrm{IRR}=2.23,95 \% \mathrm{Cl}=$ $1.74-2.87)$ compared with those discharged to voluntary status.

\section{Discussion}

We found that there was considerable change in the pattern of compulsory treatment in 2008 -2010 under the MHA 1986, and 2014 - 2016 under the MHA 2014. As we had hypothesised, the duration of the index CTO was significantly reduced under the MHA 2014 compared to the MHA 1986, as was the time spent on subsequent Orders. Unexpectedly, almost a third of patients had the order varied to an inpatient order by the AP under the MHA 2014. There was no comparable group under the 
MHA 1986, but the sensitivity analysis suggests that this group was more likely to be male and have comorbid substance use. It is possible that the high rate of return reflects the greater challenge that these patients experienced in the community, and also the greater intention to support patients to have a trial of care under a СТО. It is also possible that this apparent change over time reflects the growing pressure to discharge people from inpatient care on a СТО in order to free up inpatient beds to meet demand.

From a practitioner's perspective the changes between the MHA 1986 and the MHA 2014 include a requirement for more detailed information from the treating service, including stronger justification of why an order is required, and why there is a preference for an inpatient over a community treatment order. This reflects the enhanced role of the external review body (MHT). The increase in the number of orders varied from community to inpatient may reflect people being put on a CTO at an earlier stage of treatment as intended by the shift in policy to a more recovery oriented focus of care and the direction that treatment be provided in the least restrictive environment, or may reflect limited engagement with community services with subsequent deterioration in mental state. There were also a greater proportion of orders which expired rather than being revoked after consideration by either the MHT or the AP.

We had expected that shorter orders would be associated with more episodes of care under the MHA over the subsequent two years. Instead, we found that patients had fewer episodes of being treated as a compulsory patient under a СTO under the MHA 2014 compared with the MHA 1986. This is consistent with the aims of the MHA 2014 to support voluntary treatment. If the CTO was varied or revoked by the AP, patients were least likely to have a further CTO under both legislative regimes, while those who became disengaged from treatment services such that their СТO expired were less likely to have a further CTO under the MHA 2014 than under the MHA 1986.

These changes to fewer and shorter periods of compulsory care suggest that the expressed aims of the government in reforming mental health legislation have been realised. Does this mean that users of the mental health system have been more empowered to seek treatment without needing the rights and protections of compulsory status, and that we have implemented recovery oriented care? Unfortunately our data does not help us to know whether outcomes or patient experience have improved. Also, we only considered changes in legal status and inpatient admissions, not all contacts with mental health services. This is relevant since it is expected that more accessible and assertive treatment might result in better engagement, and earlier intervention. Without knowing the 
frequency and duration of community contacts we are not able to comment whether there was greater engagement with community treatment under the MHA 2014, or whether there has been a change in access or outcome.

It is also worthwhile to consider what other contextual issues may have impacted on these service changes. Victoria was a leader in closing the large stand-alone bed based services and developing innovative community mental health services in the 1990s (Gerrand, 2005). Much has changed since then with some commentators noting an increasing distance between what was promised and what was delivered through supposed reforms (Singh and Castle, 2007). On a per capita basis, Victoria had the highest per capita expenditure on mental health in $1992-93$, but by $2015 / 16$ Victoria had the lowest per capita spend on mental health across Australia (AIHW 2017, Table EXP 4)(Australian Institute of Health and Welfare, 2017). The acute bed base dropped from 18.1 per 100,000 in 2008/09 to 17.2 in 2015/16 (AlHW 2017, Table FAC 13) compared to the national average of 29.4. In 2015/16 Victoria had the lowest number of full time equivalent staff with 118.2 per 100,000 population compared with the national average of 133.3 (AlHW, Table FAC 37) which suggests that there may be less ability to provide assertive care in the community. In summary, on a per capita basis, we are spending less, have fewer beds and fewer staff than comparable States in Australia despite a significant increase in population.

Increased population in the absence of proportional increases in capacity has resulted in increased pressure on state funded health services and mean that a comparatively lower proportion of the population accesses public mental health care. Victoria's mental health services annual report shows that the proportion of the population accessing state funded mental health services has fallen to 1.08\% (Victorian Government, 2017). This compares to a national average of 1.8\% (AIHW KPI 8.1). This relative reduction in service availability is likely to impact on the effectiveness of treatment, whether services can be accessed early in the course of illness or relapse and therefore on the utilisation of compulsory orders. However, it is unclear what impact these changes have had on how mental health legislation is utilised in the clinical setting.

Swanson and Swartz suggest that factors such as differing legislative regimes, funding levels, and service systems mean that the gold standard evidence of CTO effectiveness will always be elusive (Swanson JW, 2014). O'Reilly and Vingilis (2017) point to the complexity of factors impacting the use and effectiveness of CTO (O'Reilly and Vingilis, 2017). Our study found that a substantial number of those placed on a СTO under the MHA 2014 were unable to be managed in the community and had 
their order varied to an inpatient order. We also found that the duration of a СTO has an impact on future need for compulsory treatment. Harris et al (2018) found that while on a СTO there was a delay in readmission and increased community care. Our study found that the reformed MHA has been successful in its intent to reduce the use and duration of compulsory orders. This conclusion needs to be considered in the service context. Further research should consider inclusion of patient outcome such as Health of the Nation Outcome Scales (HoNOS), duration of community contact, and patient experience to better understand whether the policy objectives have been achieved while retaining or improving experience of care and health outcomes. It should be noted that our data relates to the first two and a half years after the commencement of reformed legislation and so may not reflect the full impact of intended reforms.

\section{Acknowledgements}

The data set was provided by the Department of Health and Human Services, Victoria with the kind assistance of Mr Lachlan Rimes. 
Table 1. Comparison between MHA 1986 and MHA 2014.

\begin{tabular}{|c|c|c|}
\hline & MHA 1986 & MHA 2014 \\
\hline $\begin{array}{l}\text { Definition of Mental } \\
\text { Illness }\end{array}$ & $\begin{array}{l}\text { Mental illness is a medical } \\
\text { condition that is characterised } \\
\text { by a significant disturbance of } \\
\text { thought, mood, perception or } \\
\text { memory }(s 8(1 \mathrm{~A}))\end{array}$ & Definition unchanged (s4(1)) \\
\hline $\begin{array}{l}\text { Overarching } \\
\text { legislative intent }\end{array}$ & $\begin{array}{l}\text { Includes Objects (s4) and } \\
\text { Principles of treatment and } \\
\text { care }(\mathrm{s} 6 \mathrm{~A}) \text { to emphasise least } \\
\text { restrictive environment and } \\
\text { treatment in the community. }\end{array}$ & $\begin{array}{l}\text { Includes Objectives (s10) and } \\
\text { mental health principles (s11) to } \\
\text { promote rights, recovery, } \\
\text { participation, with voluntary } \\
\text { treatment preferred. }\end{array}$ \\
\hline Naming & Involuntary patient & Compulsory Patient \\
\hline Order Stages & $\begin{array}{l}\text { Recommendation, Treatment } \\
\text { order made within } 24 \text { hours. } \\
\text { Duration max } 12 \text { months } \\
\text { unless discharged by AP or } \\
\text { MHRB }\end{array}$ & $\begin{array}{l}\text { Assessment Order }-24 \text { hours } \\
\text { Temporary Treatment Order } \\
\text { (TTO) - } 28 \text { days } \\
\text { Treatment Order - Inpatient } \\
\text { Order (ITO) max } 6 \text { months unless } \\
\text { discharged by AP } \\
\text { Community Treatment Order } \\
\text { (CTO) max } 12 \text { months }\end{array}$ \\
\hline Criteria & $\begin{array}{l}\text { The person } \\
\text { - } \quad \text { appears to be mentally } \\
\text { ill }(\mathrm{s} 8(1)(\mathrm{a})) ; \text { and } \\
\text { - } \quad \text { requires immediate } \\
\text { treatment }(\mathrm{s} 8(1)(\mathrm{b})) ; \\
\text { and } \\
-\quad \text { necessary for health } \\
\text { and safety (whether to } \\
\text { prevent deterioration) } \\
\text { or for the protection of } \\
\text { members of the public } \\
\text { (s8(1)(c)); and } \\
\text { has refused or unable } \\
\text { to consent to treatment } \\
\text { (s8(1)(d)); and } \\
\text { cannot receive } \\
\text { treatment in a manner } \\
\text { less restrictive } \\
\text { (s8(1)(e)). }\end{array}$ & $\begin{array}{l}\text { The person } \\
\text { - } \\
\text { has a mental illness } \\
\text { (s5(a)); and } \\
\text { - } \\
\text { needs immediate } \\
\text { treatment to prevent } \\
\text { serious deterioration in } \\
\text { the person's mental or } \\
\text { physical health; or serious } \\
\text { harm to self/others } \\
\text { (s5(b)); and } \\
\text { immediate treatment will } \\
\text { be provided if the person } \\
\text { is subject to a TTO or TO } \\
\text { (s5(c)); and } \\
\text { no less restrictive means } \\
\text { reasonably available } \\
\text { (s5(d)) }\end{array}$ \\
\hline External Review & $\begin{array}{l}\text { MHRB* - Within } 8 \text { weeks and } \\
\text { annually. } \\
\text { Reviews decision by Authorised } \\
\text { Psychiatrist (AP) }\end{array}$ & $\begin{array}{l}\mathrm{MHT}^{*} \text { - Within } 28 \text { days and when } \\
\text { order due to expire } \\
\text { Makes Order and sets duration }\end{array}$ \\
\hline Discharge/Revocation & $\begin{array}{l}\text { If AP considers criteria in s8(1) } \\
\text { do not apply, must discharge }\end{array}$ & $\begin{array}{l}\text { An AP who determines that the } \\
\text { treatment criteria do not apply, }\end{array}$ \\
\hline
\end{tabular}




\begin{tabular}{|l|l|l|}
\hline & $\begin{array}{l}\text { the person from the order } \\
\text { (s37) }\end{array}$ & $\begin{array}{l}\text { must immediately revoke the } \\
\text { order (s61) }\end{array}$ \\
\hline Capacity & Not explicitly included & $\begin{array}{l}\text { Presumption that person has } \\
\text { capacity to give informed consent } \\
\text { included (s70) }\end{array}$ \\
\hline Decision making & Substituted decision making & $\begin{array}{l}\text { Supported decision making } \\
\text { strongly encouraged }\end{array}$ \\
\hline $\begin{array}{l}\text { Mechanisms to assist } \\
\text { patient }\end{array}$ & $\begin{array}{l}\text { Right to a second opinion, but } \\
\text { could be from within service }\end{array}$ & $\begin{array}{l}\text { Independent Mental Health } \\
\text { Advocacy } \\
\text { Second Psychiatric Opinion } \\
\text { Scheme (Division 4) } \\
\text { Mental Health Complaints } \\
\text { Commission (Part 10) } \\
\text { Nominated persons (Division 4) } \\
\text { Advance Statements (Division 3) }\end{array}$ \\
\hline
\end{tabular}

*MHRB - Mental Health Review Board; MHT - Mental Health Tribunal 
Table 2. Demographics of individuals at index Сто

\begin{tabular}{|c|c|c|c|c|}
\hline & $\begin{array}{r}\text { MHA (1986 } \\
(n=1,478)\end{array}$ & $\begin{array}{r}\text { MHA (2014) } \\
(n=1,297)\end{array}$ & $\begin{array}{r}\text { Absolute decrease } \\
\text { in percentage } \\
(95 \% \mathrm{Cl})\end{array}$ & $\begin{array}{r}\text { Chi-squared } p \text { - } \\
\text { value for } \\
\text { independence }\end{array}$ \\
\hline Index CTO Discharge Type & & & & 0.007 \\
\hline MHT revoke & $80(5.4 \%)$ & $55(4.2 \%)$ & $1.2(-0.4,5.3)$ & \\
\hline Expiration of order & $95(6.4 \%)$ & $122(9.4 \%)$ & $-2.9(-5.0,-0.9)$ & \\
\hline Authorised Psychiatrist Revoke & $1,303(88.2 \%)$ & $1,120(86.4 \%)$ & $1.8(-0.7,4.3)$ & \\
\hline Sex & & & & 0.006 \\
\hline Female & $596(40.3 \%)$ & $457(35.2 \%)$ & $5.1(1.5,8.7)$ & \\
\hline Male & $882(59.7 \%)$ & $840(64.8 \%)$ & & \\
\hline Age at Index СТО End & & & & $<0.001$ \\
\hline 16-24 (Youth) & $138(9.3 \%)$ & 79 (6.1\%) & $3.2(1.3,5.2)$ & \\
\hline $25-34$ & $415(28.1 \%)$ & $287(22.1 \%)$ & $6.0(2.7,9.2)$ & \\
\hline $35-49$ & $570(38.6 \%)$ & $567(43.7 \%)$ & $-5.2(-8.8,-1.5)$ & \\
\hline $50-65$ & $270(18.3 \%)$ & $288(22.2 \%)$ & $-3.9(-6.9,-0.9)$ & \\
\hline 66-95 (Aged) & $85(5.8 \%)$ & 76 (5.9\%) & $-0.1(-1.9,1.6)$ & \\
\hline Location & & & & $<0.001$ \\
\hline Rural & $310(21.0 \%)$ & $182(14.0 \%)$ & $6.9(4.1,9.7)$ & \\
\hline Urban & $1,168(79.0 \%)$ & $1,115(86.0 \%)$ & & \\
\hline Time on Order & & & & $<0.001$ \\
\hline 3 to 6 months & 294 (19.9\%) & $441(34.0 \%)$ & $-14.1(-17.4,-10.8)$ & \\
\hline 6 months to 1 year & $772(48.8 \%)$ & $518(39.9 \%)$ & $8.9(5.2,12.6)$ & \\
\hline$>1$ year & $462(31.3 \%)$ & $338(26.1 \%)$ & $5.2(1.8,8.6)$ & \\
\hline
\end{tabular}


Table 3. Incidence Rates in the two years following index СТО discharge by discharge reason

\begin{tabular}{|c|c|c|c|c|}
\hline Event & Discharge Reason & $\begin{array}{l}\text { Mean events } \\
\text { MHA(1986) }\end{array}$ & $\begin{array}{l}\text { Mean events } \\
\text { MHA(2014) }\end{array}$ & $\begin{array}{c}\text { IRR } \\
(95 \% \mathrm{Cl})\end{array}$ \\
\hline \multirow{4}{*}{$\begin{array}{l}\text { Community } \\
\text { Treatment } \\
\text { Orders }\end{array}$} & MHT Revoked & 1.53 & 1.32 & $0.86(0.48-1.56)$ \\
\hline & Expired & 2.11 & 1.57 & $0.74(0.51-1.09)$ \\
\hline & Authorised by psychiatrist & 1.44 & 1.00 & $0.69(0.61-0.79)$ \\
\hline & Overall & 1.50 & 1.06 & $0.71(0.63-0.80)$ \\
\hline \multirow{4}{*}{$\begin{array}{l}\text { Inpatient } \\
\text { Treatment } \\
\text { Orders }\end{array}$} & MHT Revoked & 2.80 & 2.32 & $0.83(0.56-1.23)$ \\
\hline & Expired & 3.46 & 2.34 & $0.68(0.48-0.96)$ \\
\hline & Authorised by psychiatrist & 2.97 & 2.34 & $0.79(0.72-0.86)$ \\
\hline & Overall & 3.00 & 2.34 & $0.78(0.72-0.85)$ \\
\hline \multirow{4}{*}{$\begin{array}{l}\text { Inpatient } \\
\text { Admissions }\end{array}$} & MHT Revoked & 2.56 & 2.68 & $1.05(0.72-1.53)$ \\
\hline & Expired & 3.32 & 3.24 & $0.98(0.70-1.36)$ \\
\hline & Authorised by psychiatrist & 2.70 & 2.97 & $1.10(1.01-1.20)$ \\
\hline & Overall & 2.74 & 2.98 & $1.09(1.00-1.18)$ \\
\hline
\end{tabular}

Table 4. Days spent on order (community and inpatient treatment orders) in the two years following index СTO discharge by discharge reason

\begin{tabular}{lccc}
\hline Discharge Reason & $\begin{array}{c}\text { Mean under } \\
\text { MHA (1986) }\end{array}$ & $\begin{array}{c}\text { Mean under } \\
\text { MHA(2014) }\end{array}$ & $\begin{array}{c}\text { IRR } \\
(\mathbf{9 5 \% ~ C I )}\end{array}$ \\
\hline MHT Revoked & 459.00 & 327.74 & $0.71(0.40-1.27)$ \\
\hline Expired & 757.74 & 344.05 & $0.45(0.32-0.65)$ \\
\hline Authorized by psychiatrist & 455.17 & 455.17 & $0.79(0.70-0.89)$ \\
\hline \multicolumn{1}{c}{ Overall } & 479.22 & 357.15 & $0.75(0.66-0.84)$ \\
\hline
\end{tabular}

Table 5. Adjusted Logistic Regression of having an admission or Treatment Order

\begin{tabular}{lccc}
\hline Event & $\begin{array}{c}\text { Adjusted Odds } \\
\text { MHA(1986) }\end{array}$ & $\begin{array}{c}\text { Adjusted Odds } \\
\text { MHA (2014) }\end{array}$ & $\begin{array}{c}\text { AOR } \\
\text { (95\% Cl) }\end{array}$ \\
\hline Community Treatment Orders & 0.309 & 0.291 & $0.92(0.77-1.08)$ \\
\hline Inpatient Treatment Orders & 0.368 & 0.379 & $1.05(0.89-1.23)$ \\
\hline & & & \\
\hline Inpatient Admissions & 0.408 & 0.541 & $1.74(1.49-2.03)$ \\
\hline
\end{tabular}

Note: adjusted for Age at Index CTO End, sex, location and time on Index CTO 
Legislation cited

Mental Health Act 1986 (Vic)

Mental Health Act 2014 (Vic)

$\underline{\text { References }}$

Australian Institute of Health and Welfare. (2017) Mental Health Services. Canberra, Australia.

Burns T. (1999) Invited commentary: community treatment orders. Psychiatric Bulletin 23: 647-648.

Burns T and Molodynski A. (2014) Community treatment orders: background and implications of the OCTET trial. The Psychiatric Bulletin 38: 3-5.

Department of Health. (2012) A new mental health act for Victoria: Summary of proposed reforms. Melbourne: Department of Health.

Gerrand V. (2005) Can deinstitutionalisation work? Mental heatlh reform from 1990 to 1998 in Victoria, Australia. Health Sociology Review 14: 255 - 271.

Harris A, Chen W, Jones S, et al. (2018) Community treatment orders increase community care and delay readmission while in force: Results from a large population-based study. Australian \& New Zealand Journal of Psychiatry: 0004867418758920.

Hastings TJ and Gray JE. (2016) Community Treatment Orders Disconnect. The Canadian Journal of Psychiatry 61: 435-436.

Kallert Thomas W MJ, Monahan John. (2011) Coercive Treatment in Psychaitry: clinical, legal and ethical aspects, Chichester, UK: Wiley Blackwell.

Legislative Assembly. (2014) Mental Health Bill. Melbourne: Hansard.

Light E, Kerridge I, Ryan C, et al. (2012) Community treatment orders in Australia: rates and patterns of use. Australasian Psychiatry 20: 478-482.

Little J. (2018) Misrepresenting community treatment orders. Australasian Psychiatry 26: 38-40.

Maughan D, Molodynski A, Rugkåsa J, et al. (2014) A systematic review of the effect of community treatment orders on service use. Social Psychiatry and Psychiatric Epidemiology 49: 651-663.

O'Reilly R and Vingilis E. (2017) Are Randomized Control Trials the Best Method to Assess the Effectiveness of Community Treatment Orders? Administration and Policy in Mental Health and Mental Health Services Research.

Rugkåsa J, Dawson J and Burns T. (2014) CTOs: what is the state of the evidence? Social Psychiatry and Psychiatric Epidemiology 49: 1861-1871.

Singh BS and Castle DJ. (2007) Why are community psychiatry services in Australia doing it so hard? The Medical journal of Australia 187: 410-412.

Swanson JW SM. (2014) Why the Evidence for Outpatient Commitment Is Good Enough. Psychiatric Services 65: 808-811.

Swartz MS, Wilder CM, Swanson JW, et al. (2010) Assessing outcomes for consumers in New York's assisted outpatient treatment program. Psychiatric Services 61: 976-981.

United Nations. (2006) Convention on the Rights of Persons with Disabilities. New York.

Victorian Government. (2006) Charter of Human Rights and Responsibilities. Victoria: Government printer for the State of Victoria.

Victorian Government. (2014) Mental Health Act 2014. No. 26. Melbourne: Government Printer for the State of Victoria.

Victorian Government. (2017) Victoria's mental health services annual report 2016 - 2017.

Vine R, Turner S, Pirkis J, et al. (2016) Mental health service utilisation after a Community Treatment Order: A comparison between three modes of termination. Australian \& New Zealand Journal of Psychiatry 50: 363-370.

Wooldridge M. (2014a) Second reading speech for the Mental Health Bill 2014 (Vic). Hansard of the Victorian House of Assembly 470-479.

Wooldridge M. (2014b) Statement of compatibility for the Mental Health Bill 2014 (Vic). Hansard of the Victorian House of assembly, $458-470$. 
